Global Journal of Computational Intelligence Research.

ISSN 2249-0000 Volume 1, Number 1 (2011), pp. 9-19

(C) Research India Publications

https://dx.doi.org/10.37622/GJCIR/1.1.2011.9-19

\title{
Studies on Polymer Modified Recycled Aggregate Concrete
}

\author{
Ganesh D. Awchat ${ }^{1}$, Narendra M. Kanhe ${ }^{2}$ \\ and Shailendra S. Rathore ${ }^{3}$ \\ ${ }^{1}$ Doctoral Research Student of MIET, Salai Godhani, Hudkeshwar Road, \\ Nagpur-441204, Maharashtra, India \\ ${ }^{2}$ Professor in Civil Engineering \& Principal, \\ Guru Nanak Institute of Engineering \& Management, \\ Dahegaon, Kalmeshwar Road, Nagpur-441501, Maharashtra, India \\ ${ }^{3}$ Professor in Civil Engineering \& Principal, \\ Manoharbhai Patel Institute of Engineering \& Technology (MIET), \\ Kudwa, Gondia- 441614, Maharashtra, India
}

\begin{abstract}
Waste concrete with a lower degree of contamination is a potential source for the production of aggregate for concrete mix. Recycled Course Aggregate (RCA) particles consist of substantial amount of relatively soft cement paste component also they are more porous and less resistant to mechanical actions. The limitation of using RCA in new concrete is their detrimental influence on overall properties of concrete. In comparison with Normal Concrete (NC), Recycled Aggregate Concrete (RAC) shows reduction in strength and modulus of elasticity whereas increase in drying shrinkage and creep. RAC may be less durable due to increase in porosity and permeability. Thus, Ecnomical way of improving the quality and durability of RAC is by addition of polymer i.e. Styrene Butadiene Rubber (SBR Latex) which improves overall properties of concrete as suggested by [7,8] .Addition of suitable type of polymer in the form of construction chemical in concrete improves the various properties of $\mathrm{NC}$, such as strength, adhesion, resilience, water tightness, chemical resistance, durability.

In the present experimental investigations, 120 cubes $(150 \mathrm{~mm} \times 150 \mathrm{~mm}$ x $150 \mathrm{~mm}), 90$ cylinders $(150 \mathrm{~mm}-$ dia. X $300 \mathrm{~mm})$ and 90 beams $(100 \mathrm{x} 100 \mathrm{x}$
\end{abstract}


$400 \mathrm{~mm}$ ) of w/c ratio 0.47 and 0.54 were cast in four series. These specimens are casted for NC and RAC with and without polymer. The dose of polymer in RAC is varying from 5\%,10\% and $15 \%$ (by parts weight of cement). In Polymer Modified Recycled Aggregate Concrete (PMRAC), increase in compressive strength is marginal.

Flexural strength are obtained by using beam specimens, split tensile strength are from cylinder specimens and cube specimens with $15 \mathrm{~cm}$ penetration of $12 \mathrm{~mm}$ plain steel bar are used for pullout strength between concrete \& steel bar. Research shows that addition of $10 \%$ polymer in RAC significantly increases the flexural strength, split tensile strength and pull out strength. Therefore, PMRAC will only be preferred where the strength \& durability criteria for design $\&$ construction are of prime importance.

Keywords: Recycled Aggregate Concrete, Polymer, Styrene Butadiene Rubber, Polymer Modified Recycled Aggregate Concrete.

\section{Introduction}

Traditionally, waste concrete has been managed mainly through its land filling and recycling. Land filling has become a major problem, particularly in countries where land is scare. In addition to this, other problems associated with the landfill option include their silting, transportation costs, tipping fees and public opposition. Thus, recycling has gaining wider attention as a viable option for handling waste concrete.

Waste concrete can be produced from a number of different sources. The most common are demolition projects. Many concrete structures like building, bridges and roads are demolished after their service life for purposes of replacement or landscape changes. Other sources of waste include, natural disasters like earthquakes, avalanches and tornadoes: human causes like warmed bombing and structural failures. All these concrete must be managed by appropriate way in order to conserve natural resources.

The research on RAC is continued for last two decades in India. In addition to this, PMRAC is applicable to various fields of construction because of improvement in strength and deformation characteristics as compared to NC. The recycling of waste concrete has other benefits. One of the main environmental benefits is the conservation of natural resources, especially in regions where aggregates are scare. If recycling plants are centrally located and easily accessible, transport costs can be substantially minimized.

The major penalties for the use of RCA in concrete are their lower compressive strength, split tensile strength, flexural strength and lower modulus of elasticity. To over-come these drawbacks to considerable extent, it is expected in the literature [10] to produce concrete with lower w/c ratio and polymer in it.

The type of polymers generally used in modifying mortars and concretes. Selection of particular type of polymers depends on the intended use such as higher strength, durability, chemical resistance, etc. Suitable latex formulations greatly improve the shear bond, tensile and flexural strength of cement mortars and concrete. 
So, an attempt is made in this work to take advantage of past knowledge and research on polymer (latex) for the production of PMRAC.

\section{Experimental Programme Materials}

Based on physical properties of fine aggregate, Natural Course Aggregate (NCA) \& RCA, four mixes were finalized using Indian Standard recommended method of mix design suggested as per SP23:1982.

The two mixes were NA [1:1.72:3.22:0.47] \& NB [1:2.04:3.97:0.54] using natural aggregate whereas two mixes were RA [1:1.72:3.22:0.47] \& RB [1:2.04:3.97:0.54] using recycled aggregate. Also, it was decided to use same two mixes for the preparation of RAC \& SFRRAC so as to compare the various concrete properties of NAC with it.

Ordinary Portland cement of 43 grade confirming to IS 8112 was used in all mixes. The locally available sand of river Kanhan having specific gravity 2.71, fineness modulus $3.28 \&$ confirming to IS grading curve-II was used in all mixes \& locally available crushed basalt stone aggregates of Pachgaon (Nagpur) stone quarry was used in mixes of NC confirming IS 383:1970. Recycled aggregates obtained by crushing the waste material available in concrete testing laboratory of Ready Mixed Concrete Plant of Ultra-Tech Cement Limited \& concrete testing laboratory of GeoTech Services at Nagpur.

Since large size particles cause concentration of stress around particles and results in the lower strength of concrete. Considering this aspect, $20 \mathrm{~mm}$ down grade size aggregate was considered suitable for medium strength concrete as per Bhantia, Chan [5]. A complete replacement of NA with RA was considered in the mixes of RAC. Attempt was made in this research to compare concrete properties of RAC with the properties of parent source of aggregates of that region.

Table 1: shows the physical and mechanical properties of NCA and RCA.

\begin{tabular}{|l|l|l|}
\hline Tests on aggregate & $\begin{array}{l}\text { Normal(Parent)Course } \\
\text { Aggregate (NCA) }\end{array}$ & $\begin{array}{l}\text { Recycled Course } \\
\text { Aggregate (RCA) }\end{array}$ \\
\hline Fineness Modulus & 7.49 & 5.25 \\
\hline Specific gravity & 2.983 & 2.638 \\
\hline Water absorption & $0.415 \%$ & $2.972 \%$ \\
\hline Crushing value & $13.77 \%$ & $26.18 \%$ \\
\hline Impact value & $12.63 \%$ & $27.26 \%$ \\
\hline Abrasion value & $10.66 \%$ & $29.08 \%$ \\
\hline Flakiness Index & $16.69 \%$ & $13.90 \%$ \\
\hline Elongation Index & $21.26 \%$ & $35.26 \%$ \\
\hline Soundness by $\mathrm{MgSo}_{4}$ & $0.5142 \%$ & $-0.5942 \%$ \\
\hline Soundness by $\mathrm{Na}_{2} \mathrm{So}_{4}$ & $0.4263 \%$ & $-0.4464 \%$ \\
\hline
\end{tabular}


In the experimental programme, polymer i.e. Styrene Butadiene Rubber (SBR Latex) in the form of Monobond-2000 was used. Latex is milky white colloidal fluid containing 30 to $45 \%$ of rubber, the remainder being mainly water and small portion of protein and resinous materials. Monobond-2000 is milky white liquid of specific gravity of 1.05 to 1.10 and viscosity $300-500$ in cps.

\section{Mix Proportion}

Since there is no standard method of designing concrete mixes incorporating RA, the method of mix design proposed by IS 10262:1982 \& SP23:1982 was first employed to design the NAC mixes and finally NCA was fully replaced by RCA to obtain RAC mixes as per Ravande[9]. In the RAC mix, SBR Latex (polymer) in the form of Monobond-2000 is added at the dosage of 5\%,10\% and $15 \%$ by weight with respective weight of cement added. The cubes of size $15 \times 15 \times 15 \mathrm{~cm}$ were cast for trial mix.

Table 2: shows trial mix results of M30 and M20 for NC \& RAC.

\begin{tabular}{|l|l|l|l|l|}
\hline Mix type & $\begin{array}{l}\text { Aggregate } \\
\text { in mix }\end{array}$ & $\begin{array}{l}\text { Avg. compressive } \\
\text { strength } / \mathrm{mm}^{2} \\
(7 \text { days })\end{array}$ & $\begin{array}{l}\text { Avg. compressive } \\
\text { strength N/mm } \mathrm{mm}^{2}(28 \text { days })\end{array}$ & $\begin{array}{l}\text { Cement content } \\
\left(\mathrm{Kg} / \mathrm{m}^{3}\right)\end{array}$ \\
\hline Mix-1 & NCA & 28.48 & 38.21 & 379.59 \\
\hline Mix-2 & NCA & 23.67 & 33.31 & 338.18 \\
\hline Mix-1 & RCA & 27.36 & 34.61 & 379.59 \\
\hline Mix-2 & RCA & 20.12 & 31.21 & 338.18 \\
\hline
\end{tabular}

\section{Casting and Testing Specimens}

Total 120 cubes, 90 cylinders and 90 beams of $\mathrm{M}_{30}$ and $\mathrm{M}_{20}$ grade of concrete were cast in four series. Out of which, first two series were cast for NC and RAC by using two w/c ratio $0.47 \& 0.54$ and other two series were cast by adding SBR Latex at the dosage of $5 \%, 10 \%$ and $15 \%$ by weight with respective weight of cement in RAC for both mixes.

Two w/c ratios were designed in order to determine the effect of w/c ratio on the various properties of concrete i.e. compressive strength, split tensile strength, flexural strength, stress-strain behavior in compression, bond strength.

First series of casting consists of 24 cubes, 18 cylinders and 18 beams of NA \& RA confirming to $\mathrm{M}_{30}$ grade. These specimens were cast to determine compressive strength, split tensile strength and flexural strength of NC and RAC at 7 days, 28days \& 90 days. Out of total 24 cubes, 3 cubes each of NC and RAC were tested to determine pull out strength of both at 28 days.

In Second series, casting as done in first series was repeated by $\mathrm{M}_{20}$.

Third series of casting consist of 36 cubes, 27cylinders and 27 beams of $\mathrm{M}_{30}$ grade (RA) and these specimens were cast for RAC only. The parameters varied during 
casting of these specimens were polymer dosage of $5 \%, 10 \%$ and $15 \%$ by weight (with respective weight of cement). Out of 36 cubes, 3 cubes each of three variation of polymer were tested to study pull strength at 28 days.

In Fourth series, casting done in third series was repeated by $\mathrm{M}_{20}(\mathrm{RB})$.

Table 3: shows details of casting specimens.

\begin{tabular}{|c|c|c|c|c|}
\hline \multirow[t]{2}{*}{ Type of mix } & \multirow[t]{2}{*}{ Specification } & \multicolumn{3}{|c|}{ Number of specimens } \\
\hline & & Cubes & Cylinders & Beams \\
\hline \multirow[t]{5}{*}{ Mix-1 } & $\mathrm{NA}(\mathrm{NC}+0 \%$ polymer $)$ & 12 & 9 & 9 \\
\hline & RA (RAC+0\% polymer) & 12 & 9 & 9 \\
\hline & RA-1 (RAC+5\%polymer) & 12 & 9 & 9 \\
\hline & RA-2(RAC+10\% polymer) & 12 & 9 & 9 \\
\hline & RA-3(RAC+15\%polymer) & 12 & 9 & 9 \\
\hline \multirow[t]{5}{*}{ Mix-2 } & $\mathrm{NB}(\mathrm{NC}+0 \%$ polymer $)$ & 12 & 9 & 9 \\
\hline & RB (RAC+0\%polymer) & 12 & 9 & 9 \\
\hline & RB-1 (RAC+5\%polymer) & 12 & 9 & 9 \\
\hline & RB-2(RAC+10\%polymer) & 12 & 9 & 9 \\
\hline & RB-3(RAC+15\%polymer) & 12 & 9 & 9 \\
\hline \multicolumn{2}{|c|}{ Total No. of Specimen } & 120 & 90 & 90 \\
\hline
\end{tabular}

\section{Curing specification}

All cubes, cylinders and beams specimens were cured for 3 days after 24 hours of casting. After 3 days water curing specimens were taken out of water and exposed in natural sunlight for further air curing up to 90 days.5\% polymer contain in RAC is insufficient for polymerization in air curing therefore these specimens were cured in water for 28 days and after that it was air cured in natural sunlight. Other two type of PMRAC specimens were exposed to air curing for a period of 3 days to 90 days.

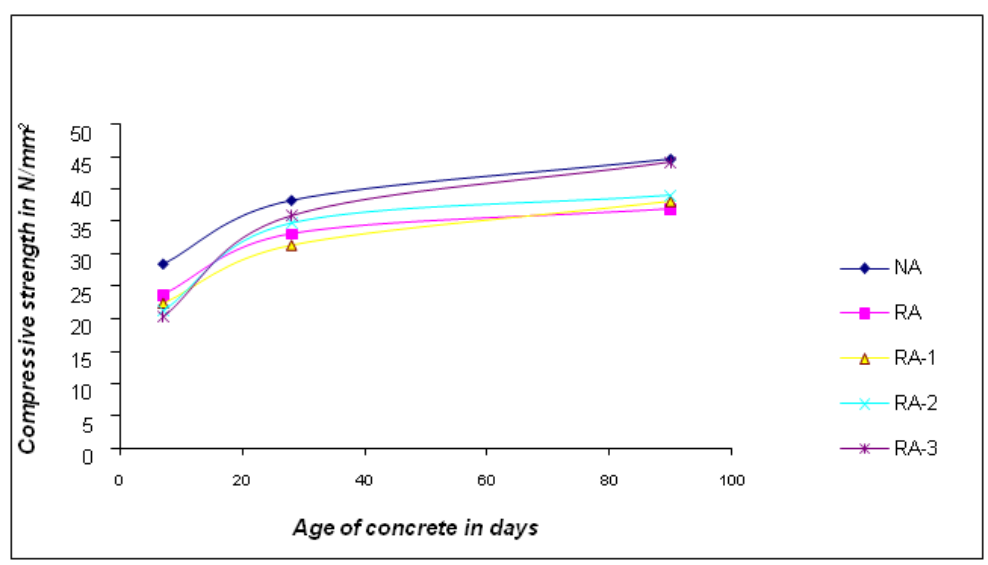

Figure 1.1: Compressive strength as a function of age. 


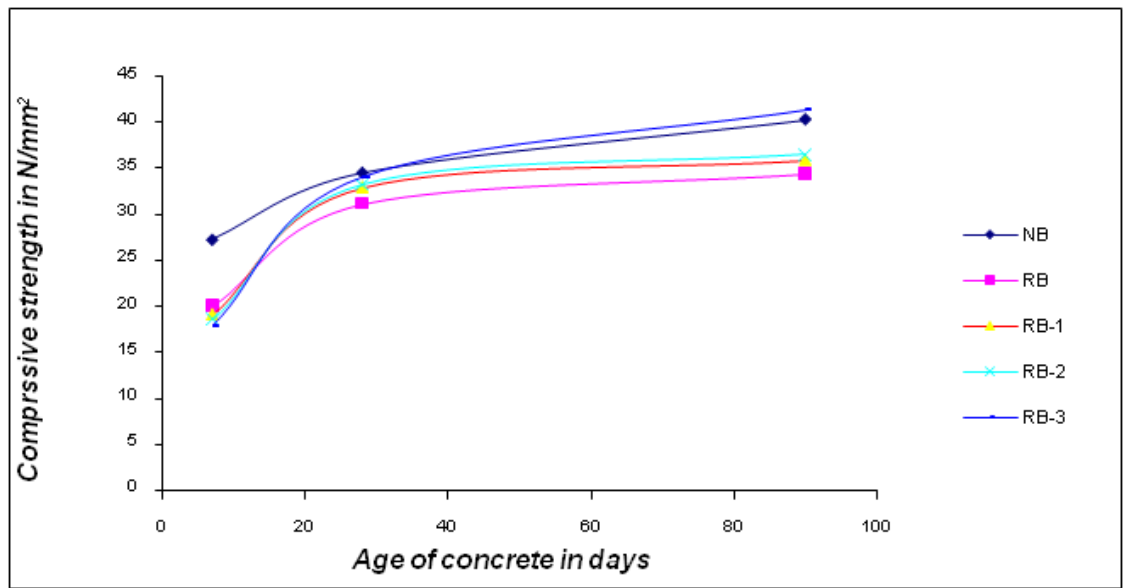

Figure 1.2: Compressive strength as a function of age.

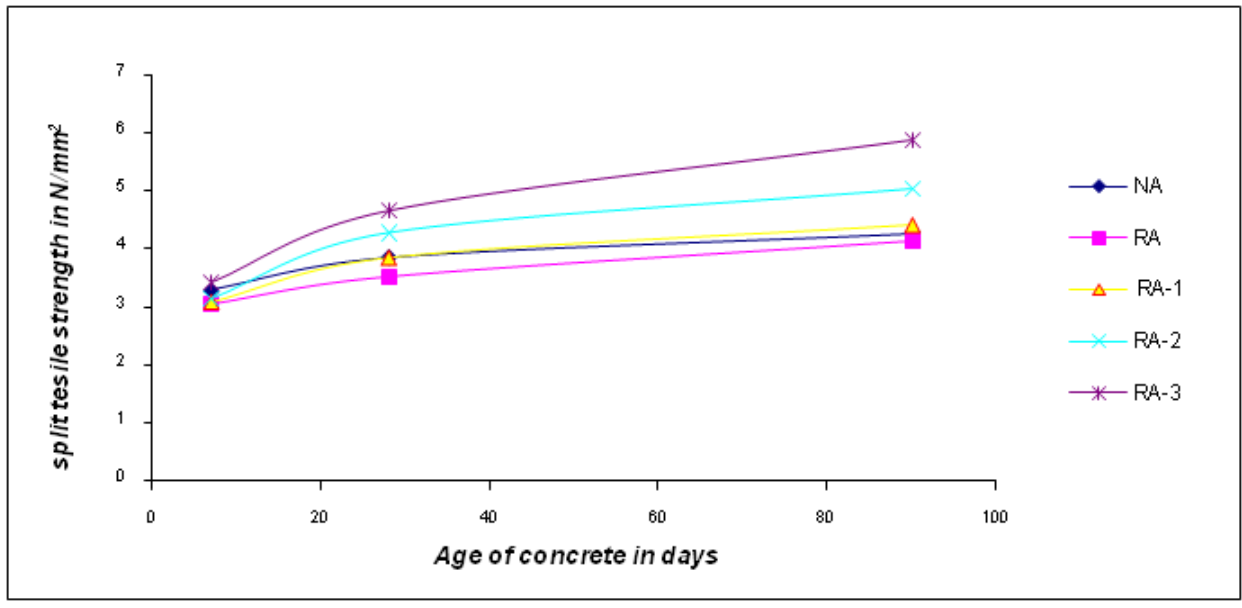

Figure 2.1: Split tensile strength as a function of age.

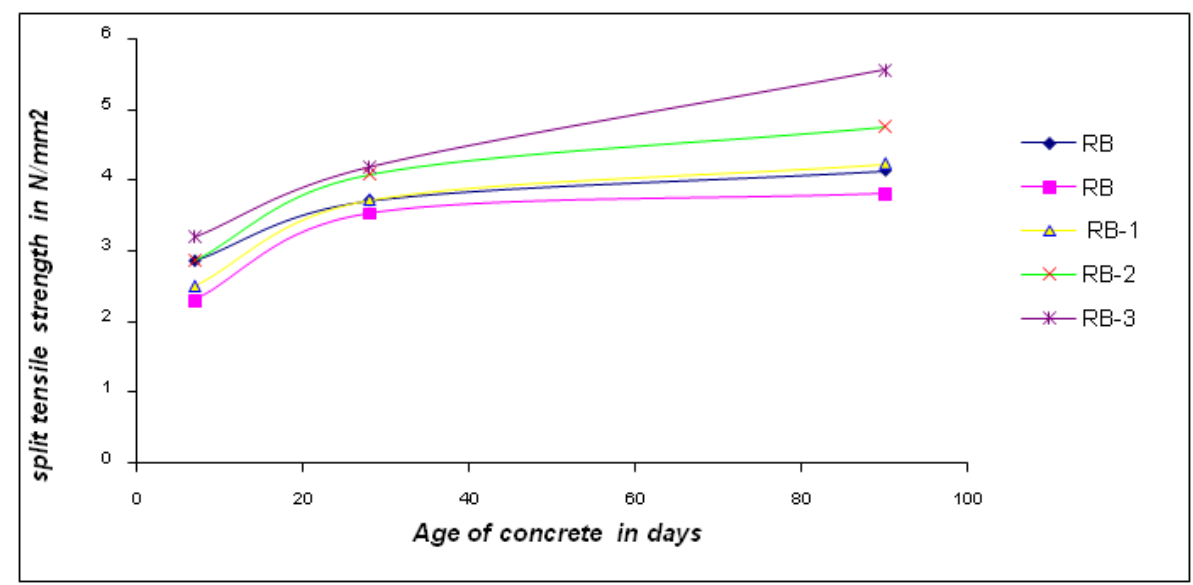

Figure 2.2: Split tensile strength as a function of age. 


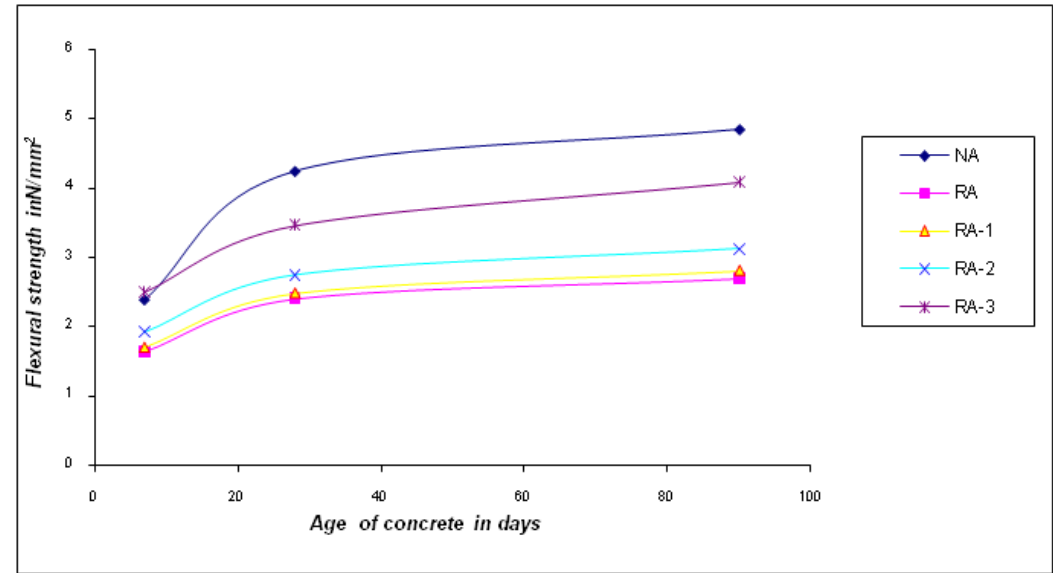

Figure 3.1: Flexural strength as a function of age.

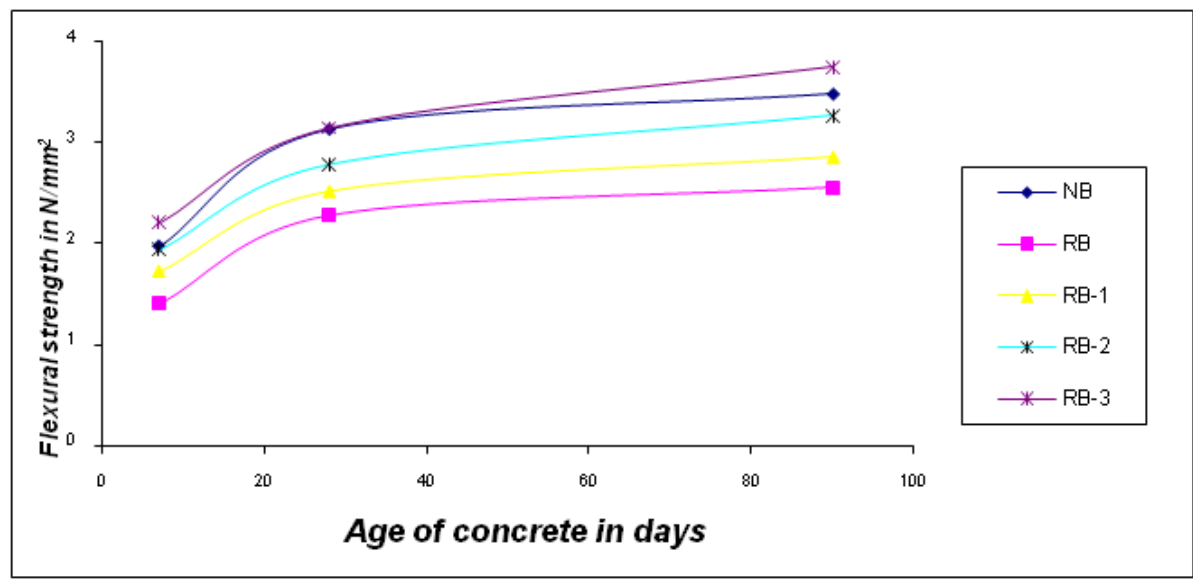

Figure 3.2: Flexural strength as a function of age.

Table 4: Pull out strength results for both mixes.

\begin{tabular}{|l|l|l|l|}
\hline $\begin{array}{l}\text { Identification of } \\
\text { specimens }\end{array}$ & $\begin{array}{l}\text { Polymer/cement } \\
\text { Ratio }(\%)\end{array}$ & $\begin{array}{l}\text { Average pull out } \\
\text { load }(\mathrm{N})\end{array}$ & $\begin{array}{l}\text { Bond strength } \\
\tau_{\mathrm{bd}}\left(\mathrm{N} / \mathrm{mm}^{2}\right)\end{array}$ \\
\hline NA & 0.0 & 37500 & 11.94268 \\
\hline RA & 0.0 & 31600 & 10.06369 \\
\hline RA-1 & 5.0 & 33000 & 10.50955 \\
\hline RA-2 & 10.0 & 35000 & 11.1465 \\
\hline RA-3 & 15.0 & 39500 & 12.57962 \\
\hline NB & 0.0 & 20400 & 6.496815 \\
\hline RB & 0.0 & 29000 & 9.23566 \\
\hline RB-1 & 5.0 & 32850 & 10.46178 \\
\hline RB-2 & 10.0 & 34000 & 10.82803 \\
\hline RB-3 & 15.0 & 38000 & 12.10191 \\
\hline
\end{tabular}




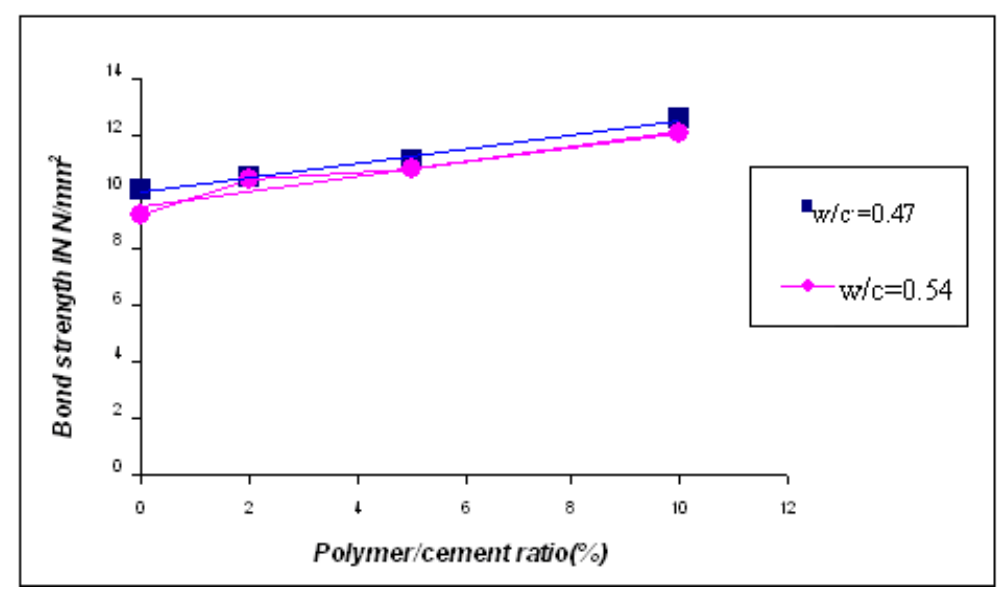

Figure 4.1: Relation between pull out strength and polymer/cement ratio for RAC.

\section{Results \& Discussion \\ Aggregate Properties \\ Specific Gravity and Water Absorption}

Tests conducted in this project work, has shown that specific gravity of RCA is 2.638 , which is lower than NCA i.e. 2.983. The basic reason is that RA consisting of unhydrated cement particles around the outer surface, which ultimately resulting into high porosity. RCA with higher porosity ultimately resulting decrease in specific gravity. In spite of this, specific gravity of RCA is within the acceptable limit as an aggregate for production of concrete.

From table 1, the water absorption of RCA is $2.557 \%$ higher than the NCA. Presoakingof aggregate is generally adopted to counter-balance the effect of water absorption. Hence; it is advisable and necessary to presoak RCA before using them for RAC.

\section{Crushing, Impact and Abrasion Values}

From table 1, it is seen that RCA is relatively weaker than that of NCA against mechanical actions. As per IS 2386 (Part-IV), the crushing and impact values should not be more than $45 \%$ for aggregate used for concrete other than wearing surfaces, and $30 \%$ for concrete used for wearing surfaces such as roads, runways and pavements. The values of crushing and impact of recycled aggregate is $26.18 \%$ and $27.26 \%$ whereas it is $13.77 \%$ and $12.63 \%$ for natural aggregate.. The abrasion value of RCA is $29.08 \%$, while it is $10.66 \%$ for NCA.The values of mechanical resistance of RCA showed that it is within permissible limit of IS 2386(Part-IV).Thus, it showed its applicability for wearing surfaces.

Soundness test on aggregate as specified in IS: $2386($ Part-V) is carried to decide ability of aggregate to resist excessive changes in volume as result of changes in physical conditions. As a guide, it can be taken that the average loss of weight after 10 cycles should not exceed $12 \%$ and $18 \%$ when tested with sodium sulphate and magnesium sulphate. 
RCA consumes sodium sulphate and magnesium sulphate resulting into gain of weight through the pores present on outer surface whereas loss of weight is observed in NCA Thus, reverse result of soundness test is observed in RCA as compared to NCA.

\section{Compressive Strength}

The variation in compressive strength of concretes as the function of age is shown in fig. The reduction in compressive strength of RAC than NC is observed in fig. 1.1 and fig. 1.2. This reduction in RAC than NC is $28 \%, 14 \%$ and $19 \%$ at the concrete age of 7,28 and 90 days, respectively.

For different percent of polymer added in RAC, 5\%, $10 \%$ and $15 \%$, there is substantial increase in compressive strength at different age of concrete. Air curing is necessary to set polymer (i.e. for polymerization), at the age of 7 days, 4 days air curing was not enough for bind aggregates mortar (first 3 days were lost in water curing).At the age of 28 and 90 days, the compressive strength is increases with increase in percentage of polymer. At the age of 90 days, the compressive strength for PMRAC with $15 \%$ polymer is $19 \%$ higher than RAC. Thus, it showed that addition of high dosage of polymer in RAC is contributing for development of additional compressive strength to marginal extent.

\section{Split Tensile Strength}

In the fig. 2.1 and 2.2, the split tensile strength is plotted as a function of age and the variation in split tensile strength in five mixes are clearly shown.

From figure, the split tensile strength of RAC without polymer is lower than that of NC. Split tensile strength of PMRAC with $15 \%$ polymer gives a considerable increase in strength than that of RAC. Polymer addition in RAC from inner molecular network in the concrete mass, therefore it strongly binds the aggregates, sand and cement. PMRAC with $15 \%$ polymer have $45 \%$ higher tensile strength than RAC at 90 days, i.e. it can be say that polymer addition gives effective results.

\section{Flexural Strength}

As shown in the fig.3.1 and 3.2, the variation of flexural strength with respective age concrete in all five mixes is clearly shown. The flexural strength of RAC is very less than that conventional concrete. Flexural strength in PMRAC increases with percentage of polymer. Increase in flexural strength in PMRAC with $15 \%$ polymer is $47 \%$ than RAC, and it increases $19 \%$ in between 28 to 90 days.

\section{Pull out Strength}

The adhesion between reinforcement and concrete is increased with percentage of polymer (i.e. polymer/ cement ratio). The fig. 4.1 shows relation between the pull out stress $\left(\tau_{\mathrm{bd}}\right)$ and the percentage of polymer in RAC. The Pull out strength was checked at the age of 28 days using standard pull out test. The bond strength values are obtained for every specimen casted for bond strength. It is $28 \%$ higher in PMRAC 
with $15 \%$ polymer than RAC. It shows linear increment with percentages of polymer. The proposed equation for pull out strength is as shown below

The correlation function for w/c ratio [0.47] $\mathrm{m}_{\mathrm{p}}$

$$
\tau_{\mathrm{bd}}=10.006+0.2516
$$

$\mathrm{m}_{\mathrm{c}}$

The correlation function for w/c ratio [0.54] is.

$$
\tau_{\text {bd }}=9.5398+0.2628 \mathrm{~m}_{\mathrm{c}}
$$

Where,

$\tau_{\mathrm{bd}}=$ Pull out strength in $\mathrm{N} / \mathrm{mm}^{2}$

$\mathrm{m}_{\mathrm{p}}=$ Mass of polymer.

$\mathrm{m}_{\mathrm{c}}=$ Mass of cement.

\section{Conclusion}

A compression of the RCA with NCA showed that the former has lower specific gravity, higher water absorption capacity, low fineness modulus, lower flakiness index \& higher elongation index. In addition, resistance to mechanical action such as impact, crushing and abrasion strength is significantly higher for RCA than NCA.

For the same mix, PMRAC has higher slump than that of NC. Therefore, the addition of polymer ultimately improves the workability of RAC. In addition to this, addition of polymer in RAC reduces water demand of RAC. As the quantity of water is reduced ultimately the w/c ratio has lower value than that of $\mathrm{NC}$.

Marginal increase in compressive strength due to addition of $15 \%$ polymer in RAC. Significant increase in split tensile \& flexural strength is observed in PMRAC with $15 \%$ polymer in it. This indicates that PMRAC with $15 \%$ polymer is optimum dose for getting required strengths. The graph of pull out strength versus polymer/cement ratio showed linear increment in both mixes. So, the quality of RAC is found to be improved considerable with the addition of polymer.

Thus, the results of this study provide a strong support for the feasibility of using RCA instead of NCA for the production of such concrete. However, more research studies on RAC are necessary for the practical application of it on large scale..

\section{Acknowledgement}

SBR (Latex) Polymer required for experimental study was received from Black Cat Enterprises (P) Limited, Nagpur, Maharashtra, India under their R\&D grant for Institutional Research is gratefully acknowledged. 


\section{References}

[1] Dhir R.., K.P., 2010, "Value Added Sustainable Use of Recycled and Secondary Aggregate in Concrete," J. ICI, pp.7-21.

[2] Desai S.B., 2010, "Use of Industrial Byproducts and Recycled Materials in Concrete Structures -An Engineer's Perspective,"J.ICI, pp.41-48.

[3] Villagran-Zaccardi, Y.A., Zega, C.A., and Di Maio A.A., 2008, "Chloride Penetration and Bonding in Recycled Concrete,"J.ASCE, pp.449-455.

[4] Otsuki N.and etal, 2003, "Influence of Recycled Aggregate on Interfacial Transition Zone, Strength, Chloride Penetration and Carbonation of Concrete," J. ASCE, pp.443-451.

[5] Banthia, N., and Chan, C., 2000, "Use of Recycled Aggregate in Plain and Fiber Reinforced Shotcrete", J.CI, pp. 41-55.

[6] Dhir R., Henderson, N.A., and. Limachiya, M.C. 1999, "Recycled Aggregate Concrete for Sustainable Development", The Indian Concrete Journal, pp.463464.

[7] Radomir J.F., and Vlastimir, S.R., 1998, "Experimental research on Polymer Modified Concrete,"J.ACI, Vol.95 (4), pp.463-469.

[8] Yannas F., and Shah, S.P., 1977, "Polymer latex modified mortar,"J.ACI, pp.61-65.

[9] Ravande, K., 1996, "Recycled Concrete- An Alternative Material of the Twenty First Century for Construction,'Int. Seminar on Civil Eng. Practices, pp.964-973.

[10] Prakash, K.B., and Krishnaswamy, K.T., 1996, "Suitability of Superplastcized Recycled Aggregate Concrete in Construction,” J.CE\&CR, pp.21-27.

[11] Ghugal, Y.M., 1994, "Polymer modified mortar material for strengthening of earthquake damaged structure,"Proc.10th Sympon Earthquake Engineering, Roorkee, India, pp.203-209.

[12] Limaye, R.G., and Kamat, M.K., 1992, "Experimental studies on polymers modifications of Cement Mortar,'J.ICI, pp.153-158.

[13] Ohama, Y., 1987, "Principle of Latex Modification and Some Typical Properties of Latex-modified Mortar and Concrete,'J.ACI, pp.511-518

[14] Nixon, P.J., 1977, "Recycled Concrete as an Aggregate for Concrete- a Review". J.MC, Vol-11, No.65, pp.371-377.

[15] Yannas F., 1977, "Waste Concrete as Aggrgate for New Concrete,"J.ACIVol.74 (37), pp.373-376.

[16] Charman, Dikeou, J.T., 1977, “Polymer Concrete,” J.ACI, pp.378-384. 